\title{
Effects of positive end-expiratory pressure on oscillated volume during high frequency chest compression in children with cystic fibrosis
}

\author{
Cara F Dosman MD FRCPC FAAP ${ }^{1}$, Peter C Zuberbuhler MD FRCPC ${ }^{1}$, Joan I Tabak RN ${ }^{1}$, Richard L Jones PhD FCCP ${ }^{2}$
}

CF Dosman, PC Zuberbuhler, JI Tabak, RL Jones. Effects of positive end-expiratory pressure on oscillated volume during high-frequency chest compression in children with cystic fibrosis. Can Respir J 2003;10(2):94-98.

OBJECTIVE: To investigate the effects of positive end-expiratory pressure (PEEP) on end-expiratory lung volume (EELV) and mean oscillated volume $\left(\mathrm{V}_{\text {osc }}\right)$ during high frequency chest compression (HFCC).

DESIGN: A clinic-based prospective intervention study.

SETTING: Pulmonary function laboratory, University of Alberta, Edmonton, Alberta.

POPULATION: Nine children with cystic fibrosis with little or no obstructive airway disease who were selected from the outpatient Cystic Fibrosis and Pediatric Pulmonary Clinics at the University of Alberta Hospital, Edmonton, Alberta.

METHODS: Each child received HFCC alone (at $10 \mathrm{~Hz}$ with chest wall pressure of $8 \mathrm{~cm} \mathrm{H} \mathrm{H}_{2} \mathrm{O}$ ) and HFCC plus PEEP. A closed circuit spirometry system was used to measure HFCC- and PEEP-induced changes in EELV, expressed as per cent baseline functional residual capacity (FRC) measured using helium dilution. An isothermic chamber permitted measurement of $\mathrm{V}_{\text {osc }}$.

RESULTS: HFCC caused a significant $9 \%$ decrease in EELV. Adding $2.0 \pm 0.3 \mathrm{~cm} \mathrm{H}_{2} \mathrm{O}$ of PEEP increased EELV back to at least the FRC level. With HFCC alone, $V_{\text {osc }}$ was significantly lower during spontaneous expiration than during spontaneous inspiration, but adding PEEP to HFCC increased $V_{\text {osc }}$, especially during spontaneous expiration.

CONCLUSIONS: Adding PEEP during HFCC prevents the decrease in EELV and increases $\mathrm{V}_{\text {osc }}$. Therefore, PEEP may improve HFCC-induced mucus clearance in children with cystic fibrosis.

Key Words: Cystic fibrosis; End-expiratory lung volume; High frequency chest compression; Positive end-expiratory pressure
Les effets d'une pression expiratoire positive sur le volume oscillant pendant une compression thoracique à haute fréquence chez des enfants atteints de fibrose kystique

OBJECTIF : Explorer les effets d'une pression expiratoire positive (PEEP) sur le volume expiratoire pulmonaire (VEP) et le volume oscillant moyen $(\mathrm{VOM})$ pendant une compression thoracique à haute fréquence (CTHF).

CONCEPTION : Étude d'intervention prospective en milieu clinique LIEU : Laboratoire de fonction pulmonaire, université de l'Alberta, Edmonton (Alberta)

POPULATION : Neuf enfants atteints de fibrose kystique présentant une maladie obstructive des voies respiratoires bénigne ou inexistante aux cliniques externes pulmonaires pédiatriques et de fibrose kystique ont été sélectionnés de la University of Alberta Hospital d'Edmonton, en Alberta. MÉTHODOLOGIE : Chaque enfant a d'abord subi une simple CTHF (à $10 \mathrm{~Hz}$, avec une pression de la paroi thoracique de $8 \mathrm{~cm} \mathrm{~d} \mathrm{H}_{2} \mathrm{O}$ ) et une CTHF accompagnée d'une PEEP. Un système de spirométrie en circuit fermé a été utilisé pour mesurer les modifications produites par la CTHF et la PEEP sur le VOM, exprimées à titre de pourcentage de la capacité résiduelle fonctionnelle (CRF) de base mesurée au moyen de dilution à l'hélium. Une chambre isothermique a permis de mesurer le VOM.

RÉSULTATS : La CTHF a provoqué une diminution significative de $9 \%$ du VEP. L'ajout de 2,0 $\pm 0,3 \mathrm{~cm}$ d' $\mathrm{H}_{2} \mathrm{O}$ de PEEP a accru le VEP pour qu'il revienne au moins au taux de la CRF. Avec la simple CTHF, le VOM était beaucoup plus bas pendant l'expiration spontanée que pendant l'inspiration spontanée, mais l'ajout de PEEP à la CTHG faisait augmenter le VOM, surtout pendant l'expiration spontanée.

CONCLUSIONS : L'ajout de la PEEP pendant la CTHF prévient la diminution du VEP et accroît le VOM. Par conséquent, la PEEP améliore peut-être la clairance muqueuse produite par la CTHF chez les enfants atteints de fibrose kystique.
$\mathrm{P}^{2}$ atients with cystic fibrosis (CF) have viscous airway mucus that is difficult to clear from the lungs and that often plugs airways, causing air trapping (1). High frequency chest compression (HFCC) is a technique that increases mucus clearance in patients with CF after short term (2-4) or long term use (5).

HFCC has comparable (6) or greater (7) effects on weight of expectorated sputum compared with conventional chest physiotherapy (CPT) and has the advantage of being self administered (6). Patients with CF have reported greater satisfaction and compliance using HFCC than with CPT (8).

With HFCC, a pneumatic vest is worn that is inflated with air; the air pressure is then cycled at frequencies between 5 and $25 \mathrm{~Hz}$ to oscillate the chest wall, lung and airway gases. This oscillatory airflow seems to break up mucus, thus lowering its viscosity and making the mucus easier to clear from the lungs (9). In addition, the compression phase of the HFCC cycle causes a high cephalad airflow velocity, which may help to

${ }^{1}$ Department of Pediatrics and ${ }^{2}$ Department of Medicine, University of Alberta, Edmonton, Alberta

Correspondence and reprints: Dr Cara F Dosman, Child Development Centre, The Hospital For Sick Children, 555 University Avenue, Toronto, Ontario M5G 1X8. Telephone 416-813-6336, fax 416-813-7437, e-mail c.dosman@utoronto.ca 
TABLE 1

\begin{tabular}{lc} 
Anthropometric and lung function data (mean \pm SEM) \\
\hline Age (years) & $12.8 \pm 2.4$ \\
Height $(\mathrm{cm})$ & $147.7 \pm 15.4$ \\
Weight $(\mathrm{kg})$ & $40.7 \pm 12.9$ \\
Weight $(\%$ of ideal weight for height) & $101.55 \pm 9.02$ \\
$\mathrm{FEV}_{1}(\mathrm{~L})$ & $2.12 \pm 0.80(80.6 \pm 16.0)^{*}$ \\
$\mathrm{FEV}_{1} / \mathrm{FVC}(\%)$ & $76.7 \pm 8.4$ \\
$\mathrm{Vital}^{*}$ capacity $(\mathrm{L})$ & $2.85 \pm 1.19(98.8 \pm 19.5)$ \\
$\mathrm{FRC}_{\mathrm{He}}(\mathrm{L})$ & $1.58 \pm 0.70(88.1 \pm 21.9)$ \\
$\mathrm{RV}_{\mathrm{He}}(\mathrm{L})$ & $0.82 \pm 0.49(106.1 \pm 39.7)$ \\
$\mathrm{RV}_{\mathrm{He}} / \mathrm{TLC} \mathrm{He}$ & $21.44 \pm 5.68(101.7 \pm 27.6)$ \\
$\mathrm{TLC}_{\mathrm{PI}} / \mathrm{TLC}_{\mathrm{He}}$ & $1.20 \pm 0.12$ \\
$\mathrm{PEEP}\left(\mathrm{cm} \mathrm{H} \mathrm{H}_{2} \mathrm{O}\right)$ & $2.01 \pm 0.30$
\end{tabular}

*Values in parentheses are per cent of predicted obtained from Polgar and Promadhat (15). FEV 1 Forced expired volume in $1 \mathrm{~s}$; FRC Functional residual capacity; FVC Forced vital capacity; He Using the helium dilution technique; PEEP Positive end-expiratory pressure; PI Using body plethysmography; $R V$ Residual volume; TLC Total lung capacity

move mucus along the airway for expectoration (10). Because the active motion of HFCC is compression of the chest, lung volumes tend to decrease until outward chest wall recoil becomes sufficient to match the compression effect of the vest. In this steady state, end-expiratory lung volume (EELV) can decrease to as low as $50 \%$ of functional residual capacity (FRC), but most patients decrease lung volume to about $90 \%$ of FRC (11). This HFCC-induced decrease in lung volume further increases an already high airway resistance and may actually decrease the effectiveness of HFCC, especially in patients who develop airway closure or who are expiratory flow limited near FRC.

Falk et al (12) reported that adding positive end-expiratory pressure (PEEP) during spontaneous breathing increased the volume of sputum expectoration in patients with CF. However, van der Schans et al (13) subsequently reported that PEEP applied during spontaneous breathing had no significant effect on mucus clearance in patients with CF. In 1998, Perry et al (14) studied patients with severe chronic obstructive pulmonary disease (COPD). They showed that mean oscillated volume $\left(\mathrm{V}_{\text {osc }}\right)$, which is the rapid air movement caused by HFCC, was only $6.0 \mathrm{~mL}$. However, after adding sufficient PEEP to return EELV back to FRC, $\mathrm{V}_{\text {osc }}$ increased to $9.4 \mathrm{~mL}$ ( $57 \%$ increase). Perry et al argued that the increased $V_{\text {osc }}$ resulted from the PEEP-induced increase in EELV, causing a decrease in airway resistance and minimizing the degree of airway closure caused by HFCC alone. Because $\mathrm{V}_{\text {osc }}$ is thought to be the factor responsible for enhancing mucus clearance (11), $\mathrm{V}_{\text {osc }}$ is critical to the effectiveness of HFCC.

In the present study, we investigated the effects of HFCC and HFCC plus PEEP in pediatric patients with CF who had little or no airway obstruction, but who were all receiving regular CPT treatments. To counteract the HFCC-induced decrease in EELV, PEEP was added to increase EELV back to FRC. We postulated that by maintaining EELV closer to FRC, airway resistance would be lower than without PEEP, and that $V_{\text {osc }}$ would increase. This study examined the effects of HFCC alone, and on the effects of HFCC plus PEEP on EELV and $\mathrm{V}_{\text {osc }}$.

\section{PATIENTS AND METHODS}

The present study was approved by the University of Alberta Faculty of Medicine Research Ethics Board, Edmonton, Alberta. Nine pediatric patients with CF participated as research patients in this study. The patients were selected from the outpatient Cystic Fibrosis and Pediatric Pulmonary Clinics at the University of Alberta Hospital. Each patient and a parent signed an informed consent before participating. The study consisted of four girls and five boys between nine and 16 years old (mean age 12.8 years). Mean absolute forced expiratory volume in $1 \mathrm{~s}\left(\mathrm{FEV}_{1}\right) /$ forced vital capacity (FVC) was $77 \%$ (range $62 \%$ to $88 \%$ ). All patients were clinically stable and received their usual medications and CPT during the study period.

Each patient came to the pulmonary function laboratory at the same time of the day on two separate occasions over the course of one month. The HFCC and HFCC plus PEEP interventions were random and given on separate days. Each patient received $20 \mathrm{~min}$ of HFCC alone on one day. On the other day, they each received 15 min of HFCC plus PEEP, which followed 5 min of HFCC alone to establish a stable EELV.

Pulmonary function tests, including spirometry and lung volume tests, were completed on all subjects immediately before each intervention. Lung volumes were measured with the helium dilution method using a Gould 2400 PFT system (Gould, USA) and also with plethysmography using a Gould 2800 Autobox (Gould). Predicted values for spirometry and for lung volumes were obtained from Polgar and Promadhat (15). Baseline FRC was used to determine changes in EELV during HFCC. The degree of air trapping in the lungs was estimated by dividing the total lung capacity (TLC) calculated using body plethysmography (TLCPI) by that calculated using the helium dilution technique $\left(\mathrm{TLC}_{\mathrm{He}}\right.$ ) (16). Anthropometric and mean lung function data for each subject are shown in Table 1 . The mean values showed mild airway obstruction with a $\mathrm{TLC}_{\mathrm{Pl}} / \mathrm{TLC}_{\mathrm{He}}$ value of 1.20 , indicating mild air trapping (16). Ventilated lung volumes, measured by helium dilution, were normal.

A pneumatic vest system (ThAIRapy model 103, American Biosystems Inc, USA) was used to administer HFCC. The background vest pressure was set at a dial pressure of 6 , and the frequency of the superimposed pressure oscillations was set at $10 \mathrm{~Hz}$ for all subjects. This combination produced a mean external chest wall pressure of approximately $9 \mathrm{~cm} \mathrm{H}_{2} \mathrm{O}$ at the end of a spontaneous expiration and a chest wall pulse pressure of approximately $8.0 \mathrm{~cm} \mathrm{H}_{2} \mathrm{O}$ (unpublished observation).

The study was conducted with the subjects breathing from a closed circuit spirometer system (Figure 1), which allowed measurement of changes in EELV during HFCC and HFCC plus PEEP. The system included a dry rolling seal spirometer (Ohio 840, Ohio Medical Products, USA), breathing valve, oxygen supply, carbon dioxide absorber and water-filled PEEP chamber. Located near the mouth was a $20 \mathrm{~L}$ isothermic chamber filled with steel wool and connected to a Validyne MD45 $\left(9 \pm 5.0 \mathrm{~cm} \mathrm{H}_{2} \mathrm{O}\right)$ transducer. This chamber allowed measurement of the volume of air moving in and out of the mouth per oscillatory cycle $\left(\mathrm{V}_{\text {osc }}\right)$ using the reverse plethysmography method (11) by measuring the oscillatory pressure changes caused by HFCC. The spirogram and $\mathrm{V}_{\text {osc }}$ were recorded on a Gould strip chart recorder. The expired circuit contained a three-way valve that permitted the direction of expired gas around or through the PEEP chamber. The inspired oxygen con- 


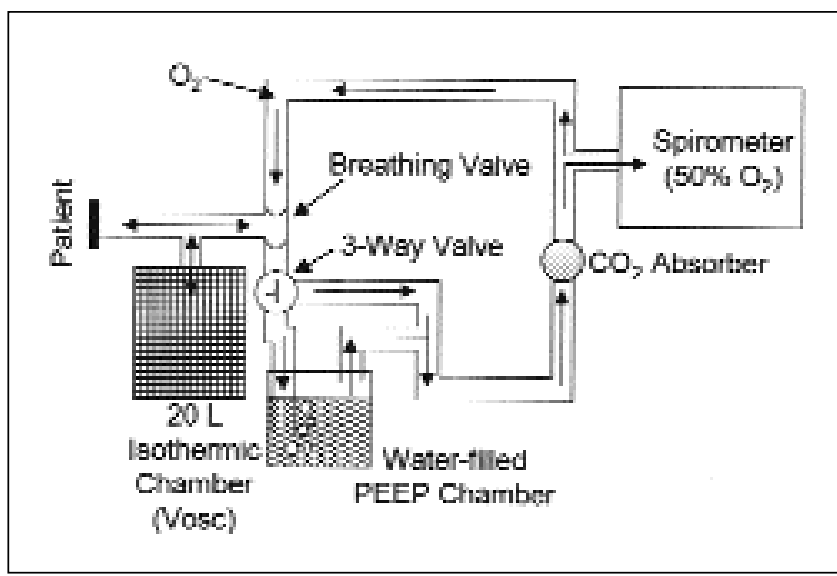

Figure 1) Diagram of the rebreathing circuit containing a spirometer which was used to measure changes in end-expiratory lung volume during high frequency chest compression (HFCC) and HFCC plus positive end-expiratory pressure (PEEP). Arrows represent the direction of airflow. The isothermic chamber was used to measure the mean oscillated volume $\left(\mathrm{V}_{\text {osc }}\right)$ by measuring the oscillatory pressure changes caused by HFCC. A three-way valve was used to bypass the PEEP chamber or to direct the exhaled gas around the PEEP chamber

centration was increased to approximately $50 \%$ at the beginning of the treatments, and it was kept at that level by adding oxygen. Carbon dioxide was removed from the exhaled gas.

PEEP was used to counteract the lung volume-reducing effect of HFCC. On the day when HFCC plus PEEP was to be studied, the amount of PEEP required during HFCC to increase lung volume back to FRC was determined before the study.

The subjects wore a deflated vest and were placed on the closed circuit system from which they breathed quietly. When EELV was stable, HFCC was started, and when EELV again stabilized, the three-way valve was rotated to direct the exhaled air through the PEEP chamber. The amount of PEEP was slowly increased until the spirometer tracing indicated that EELV had returned to the original FRC level. At this point, the subject was taken off the closed circuit, HFCC was stopped and the PEEP level was recorded. This same PEEP level (mean $2.0 \pm 0.3 \mathrm{~cm} \mathrm{H}_{2} \mathrm{O}$ ) was used in the subsequent HFCC plus PEEP intervention.

On the day of HFCC treatment, the experimental protocol required that the patients breathe for $5 \mathrm{~min}$ from the closed circuit while wearing the deflated vest. The FRC level was kept constant by adding oxygen to the circuit. When FRC was stable, HFCC was started and continued for $20 \mathrm{~min}$. Because the phase of spontaneous breathing (inspiration or expiration) has significant effects on $V_{\text {osc }}$ (11), $\mathrm{V}_{\text {osc }}$ was measured at midinspiration and midexpiration at a recorder speed of $25 \mathrm{~mm} / \mathrm{s}$. $\mathrm{V}_{\text {osc }}$ and EELV were measured $5 \mathrm{~min}$ after stabilization of EELV.

On the day of HFCC plus PEEP treatment, the protocol required that the patients begin as described above, with normal breathing and then HFCC. The HFCC alone continued for 5 min, during which EELV was stabilized and $\mathrm{V}_{\text {osc }}$ was recorded. Then, the predetermined PEEP level was added to HFCC, and the combined HFCC plus PEEP continued until EELV again stabilized, after which $\mathrm{V}_{\text {osc }}$ was measured.

Statistics were performed using GraphPad Prism software (GraphPad Software Inc, USA). Paired $t$ tests with the Bonferroni

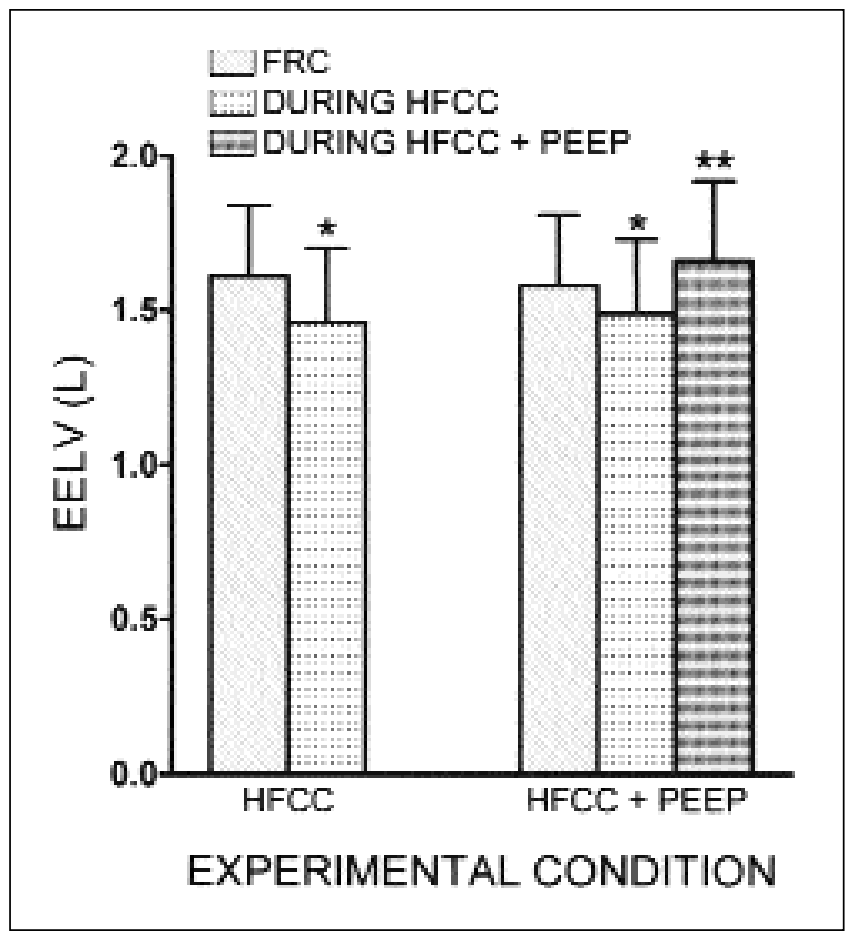

Figure 2) The effects (mean \pm SEM) of high frequency chest compression (HFCC) and HFCC plus positive end-expiratory pressure (PEEP) on end-expiratory lung volume (EELV). *Significant difference from the functional residual capacity (FRC); **Significant difference from HFCC alone

correction (17) were performed to determine whether significant differences existed between 1) FRC and EELV during HFCC and HFCC plus PEEP; and 2) $V_{\text {osc }}$ during HFCC and HFCC plus PEEP. All values are represented as mean \pm SEM.

\section{RESULTS}

The effects of HFCC and HFCC plus PEEP on EELV are shown in Figure 2. HFCC treatment alone caused a significant decrease in EELV from the FRC value of $1.61 \pm 0.23 \mathrm{~L}$ to $1.46 \pm 0.24 \mathrm{~L}$ (91\% FRC). On a separate day when the HFCC plus PEEP treatment was given, HFCC again caused a significant decrease in EELV from the FRC value of $1.58 \pm 0.23 \mathrm{~L}$ to $1.49 \pm 0.24 \mathrm{~L}$ (94\% FRC). The EELV during HFCC plus PEEP increased to $1.66 \pm 0.26 \mathrm{~L}$ and was not significantly different from FRC. Also, there was no significant difference for FRC or EELV during HFCC alone between the two experimental days.

Figure 3 shows the effects of the phase of spontaneous breathing on $\mathrm{V}_{\text {osc }}$ during HFCC alone and HFCC plus PEEP. HFCC applied without PEEP resulted in a significantly lower $\mathrm{V}_{\text {osc }}$ during spontaneous expiration $(30.9 \pm 2.1 \mathrm{~mL})$ than during spontaneous inspiration $(35.7 \pm 1.9 \mathrm{~mL})$. When PEEP was added to HFCC, increasing EELV back to FRC, $\mathrm{V}_{\text {osc }}$ increased during both inspiration (4.6\%) and expiration (13.9\%), but only the increase during expiration was statistically significant. During HFCC plus PEEP, $\mathrm{V}_{\text {osc }}$ was not significantly different between spontaneous inspiration $(37.3 \pm 1.9 \mathrm{~mL})$ and spontaneous expiration $(35.2 \pm 1.8 \mathrm{~mL})$. There was a highly significant correlation between the $\mathrm{V}_{\text {osc }}$ measured during these two 


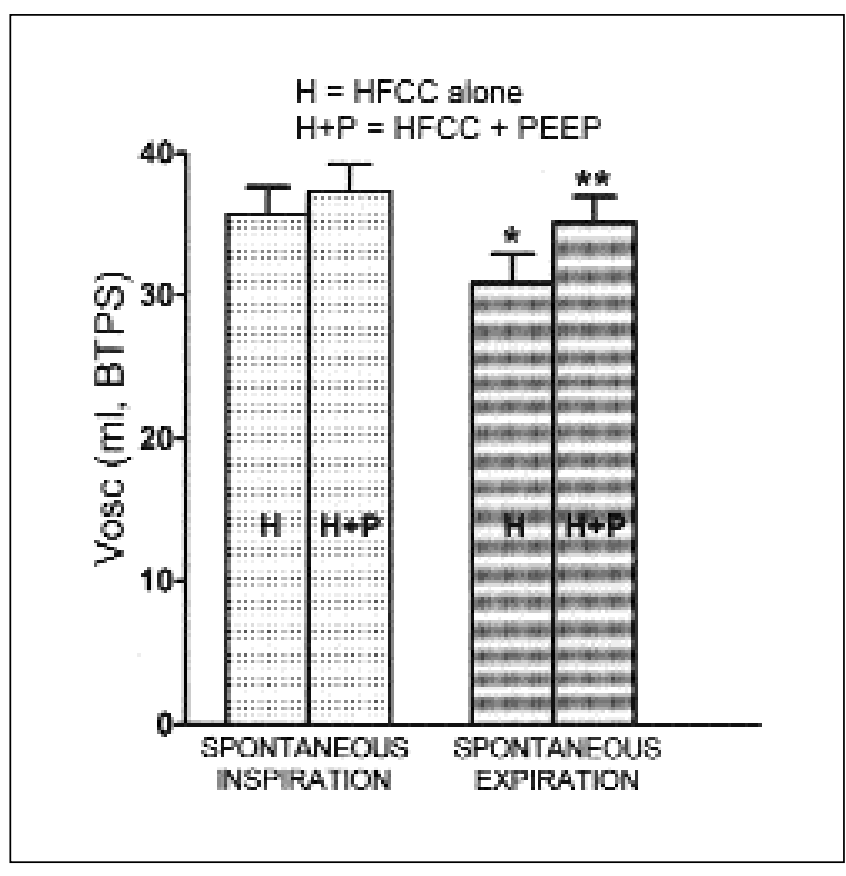

Figure 3) The effects (mean \pm SEM) of the phase of spontaneous breathing on mean oscillated volume $\left(V_{\text {osc }}\right)$ during high frequency chest compression (HFCC) (H) and HFCC plus positive end-expiratory pressure $(\mathrm{PEEP})(\mathrm{H}+\mathrm{P})$. * Significant difference between the two $\mathrm{H}$ values; **Significant difference between $H$ and $H+P$ during spontaneous expiration. BTPS Body temperature ambient pressure and saturated with water vapour

phases of breathing $(\mathrm{P}<0.001)$, indicating that patients who had low $\mathrm{V}_{\text {osc }}$ during inspiration also had low $\mathrm{V}_{\text {osc }}$ during expiration.

\section{DISCUSSION}

Several studies have shown that HFCC increases mucus clearance from the airways of patients with CF (2-4) to an extent that is comparable with or greater than the use of CPT $(6,7)$. HFCC also has the advantage of being self-administered, which can result in greater compliance than with CPT $(6,8)$. The enhanced mucus clearing effect of HFCC is caused, in part, by the oscillated airflow that creates an air mucus shear force, resulting in a lower mucus viscosity (9). Therefore, we reasoned that maximizing $V_{\text {osc }}$ would enhance the effectiveness of HFCC as a mucus-clearing modality. Perry et al (14) showed that adding PEEP to HFCC increased the $\mathrm{V}_{\text {osc }}$ in patients with severe COPD and encouraged us to test the effects of HFCC plus PEEP on $\mathrm{V}_{\text {osc }}$ in young patients with $\mathrm{CF}$ and only mild airway obstruction.

In the study by Perry et al (14) on healthy adults and patients with COPD, just enough PEEP was added to bring the EELV back to the patient's FRC. In these COPD patients, the increased lung volume during HFCC plus PEEP resulted in a $57 \%$ increase in $\mathrm{V}_{\text {osc }}$ during spontaneous expiration compared with HFCC alone. In the healthy adults, $\mathrm{V}_{\text {osc }}$ increased by $14 \%$ during expiration when PEEP was added during HFCC to return EELV back to FRC. In the present study of children with $\mathrm{CF}$ with a mean $\mathrm{FEV}_{1} / \mathrm{FVC}$ of $77 \%$, HFCC plus
PEEP also resulted in a significant $14 \%$ increase in $\mathrm{V}_{\text {osc }}$ during expiration.

Patients with CF who have severe airway obstruction may benefit from increasing lung volume with PEEP while oscillating the chest wall. On the basis of our studies to date, we believe that the addition of PEEP to HFCC is useful in patients who have enough airway obstruction to cause airway closure at lung volumes close to FRC. In these patients, the decrease in EELV caused by HFCC results in closure of some airways (18) with fewer patent airways, thus exaggerating airway resistance and decreasing $\mathrm{V}_{\text {osc }}$.

Another emerging concept of how airway obstruction limits $V_{\text {osc }}$ and flow can be obtained from analyzing the position of the tidal breathing flow-volume loop relative to the maximal flow-volume loop (19). If the expiratory portion of a normal tidal expiration reaches the maximal flow rate, then, by definition, there is flow limitation. Flow limitation may be an important constraint to the effectiveness of HFCC. Tidal expiratory flow cannot be increased when there is flow limitation, unless tidal volume is moved to a higher lung volume where maximal expiratory flow exceeds tidal expiratory flow. PEEP is a way to force breathing at higher lung volumes, thus reducing the possibility of flow limitation. Although this concept requires further exploration, it is possible that lung volumes have to be increased well above FRC in patients with moderate or severe airway obstruction to have the greatest impact on $\mathrm{V}_{\text {osc }}$ and to maximize the effectiveness of HFCC in these patients. For patients with mild airway obstruction, like the patients in the present study, increasing EELV only back to the FRC level may be sufficient to improve mucus clearance during HFCC plus PEEP. PEEP may have less effect in people with normal body weight. Scholz et al (20) found that in anesthetized adults ventilated with external chest wall oscillation, when continuous positive airway pressure was added, there was more positive effect on arterial carbon dioxide in subjects with obesity than in those with normal body build. The majority of children in our study had a weight greater than 95\% (normal percentage) (21) of ideal weight for height, while the remainder were less than $90 \%$ of ideal weight for height; none were obese. In light of the findings by Scholz et al, this may imply that it is the presence of airway obstruction in children with CF that results in greater impact from PEEP, even though our study results were similar to the $\mathrm{V}_{\text {osc }}$ increase seen in the healthy adults in the study by Perry et al.

Some of the limitations of our study were the relatively small number of participating children and their mild degree of air trapping. A larger sample size, as well as studying children with CF with more severe lung disease, could potentially yield greater increases in EELV and $\mathrm{V}_{\text {osc }}$ from adding PEEP during HFCC. As well, we did not show what effects HFCC plus PEEP may have had if the children had not simultaneously continued their usual CPT. Comparing the use of HFCC plus PEEP with CPT in these children may clarify similarities and differences in their clinical efficacy. In addition, measuring the effects of improved $V_{\text {osc }}$ on mucus clearance and gas exchange might have further enhanced our understanding of the physiological significance and clinical usefulness of HFCC plus PEEP as a mucus-clearing modality in children with CF and airway obstruction. 


\section{CONCLUSIONS}

Oscillated airflow is thought to be the factor responsible for enhancing mucus clearance during HFCC (9). In pediatric patients with CF, the addition of a small amount of PEEP during HFCC prevented the HFCC-induced decrease in EELV and increased $\mathrm{V}_{\text {osc }}$.

During HFCC, PEEP significantly improved $\mathrm{V}_{\text {osc }}$ during expiration. This may improve the effectiveness of HFCC in clearing airway secretions and may be critical in the therapeutic use of HFCC in patients with airway obstruction.

ACKNOWLEDGEMENTS: This study was supported in part by a grant from American Biosystems Inc. The results and conclusions are strictly those of the authors and should not be attributed to the sponsoring agency. The authors gratefully acknowledge the assistance of Thomas Ryan $\mathrm{PhD}$, Technical Director, Pulmonary Laboratory, University of Alberta, Edmonton, Alberta.

\section{REFERENCES}

1. Kruhlak RT, Jones RL, Brown NE. Regional air trapping before and after exercise in young adults with cystic fibrosis. West J Med 1986;145:196-9.

2. Hansen LG, Warwick WJ, Hansen KL. Mucus transport mechanisms in relation to the effect of high-frequency chest compression (HFCC) on mucus clearance. Pediatr Pulmonol 1994;17:113-8.

3. Arens R, Gozal D, Omlin KJ, et al. Comparison of high frequency chest compression and conventional chest physiotherapy in hospitalized patients with cystic fibrosis. Am J Respir Crit Care Med 1998;150:1154-7.

4. Warwick WJ. Airway clearance by high-frequency chest compression. Pediatr Pulmonol 1992;12(Suppl 8):138-9.

5. Warwick WJ, Hansen LG. The long-term effect of high-frequency chest compression therapy on pulmonary complications of cystic fibrosis. Pediatr Pulmonol 1991;11:265-71.

6. Scherer TA, Barandun J, Martinez E, Wanner A, Rubin EM. Effects of high-frequency oral airway and chest wall oscillation and conventional chest physical therapy on expectoration in patients with stable cystic fibrosis. Chest 1998;113:1019-27.

7. Kluft J, Beker L, Castagnino M, Gaiser J, Chaney H, Fink RJ. A comparison of bronchial drainage treatments in cystic fibrosis. Pediatr Pulmonol 1996;22:271-4

8. Oermann CM, Swank PR, Sockrider MM. Validation of an instrument measuring patient satisfaction with chest physiotherapy techniques in cystic fibrosis. Chest 2000;118:92-7.

9. King M, Phillips DM, Gross D, Vartian V, Chang HK, Zidulka A. Enhanced tracheal mucus clearance with high frequency chest wall compression. Am Rev Respir Dis 1983;128:511-5.

10. Hansen LG, Warwick WJ. High-frequency chest compression system to aid in clearance of mucus from the lung. Biomed Instrum Technol 1990;24:289-94.

11. Jones RL, Lester RT, Brown NE. Effects of high-frequency chest compression on respiratory systems mechanics in normal subjects and cystic fibrosis patients. Can Respir J 1995;2:40-6.

12. Falk M, Kelstrup M, Andersen JB, et al. Improving the ketchup bottle method with positive expiratory pressure, PEP, in cystic fibrosis. Eur J Respir Dis 1984;65:423-32.

13. van der Schans CP, van der Mark TW, deVries G, et al. Effect of positive expiratory pressure breathing in patients with cystic fibrosis. Thorax 1991;46:252-6.

14. Perry RJ, Man GC, Jones RL. Effects of positive end-expiratory pressure on oscillated flow rate during high-frequency chest compression. Chest 1998;113:1028-33.

15. Polgar G, Promadhat V, eds. Pulmonary Function Testing in Children Techniques and Standards. Philadelphia: WB Saunders Co, 1971.

16. Morris AH, Kanner RE, Crapo RO, Gardner RM, eds. Clinical Pulmonary Function Testing - A Manual of Uniform Laboratory Procedures. Salt Lake City: Intermountain Thoracic Society, 1984.

17. Hassard TH, ed. Understanding Biostatistics. St Louis: Mosby Yearbook, 1991:85.

18. Leblanc P, Ruff F, Milic-Emili J. Effects of age and body position on "airway closure" in man. J Appl Physiol 1970;28:448-51.

19. Johnson BD, Weisman IM, Zeballos RJ, Beck KC. Emerging concepts in the evaluation of ventilatory limitation during exercise: The exercise tidal flow-volume loop. Chest 1999;116:488-503.

20. Scholz SE, Sticher J, Häufler G, Muller M, Boning O, Hempelmann G. Combination of external chest wall oscillation with continuous positive airway pressure. Br J Anaesth 2001;87:441-6.

21. Rudolph AM, Hoffman JIE, Rudolph CD, eds. Rudolph's Pediatrics. Connecticut: Appleton \& Lange, 1996:1014. 


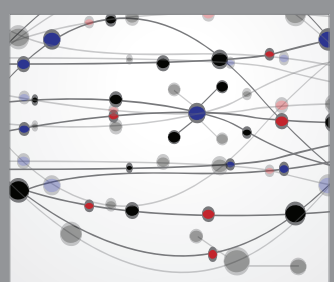

The Scientific World Journal
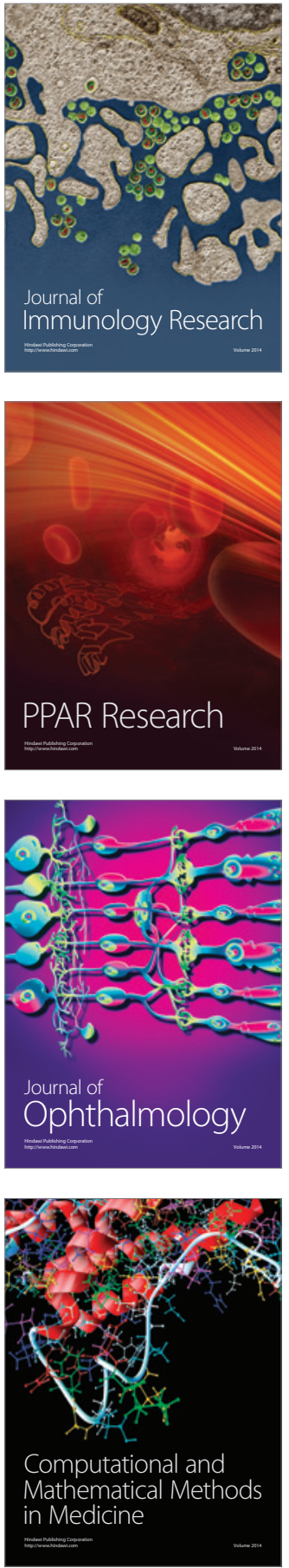

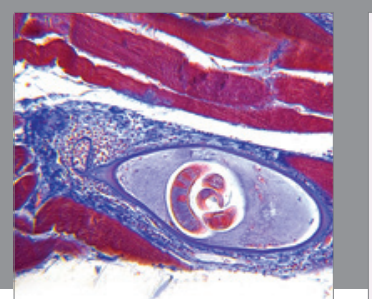

Gastroenterology Research and Practice

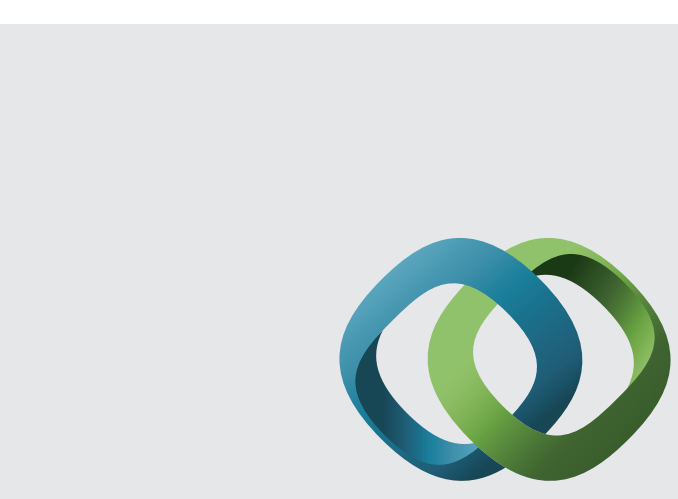

\section{Hindawi}

Submit your manuscripts at

http://www.hindawi.com
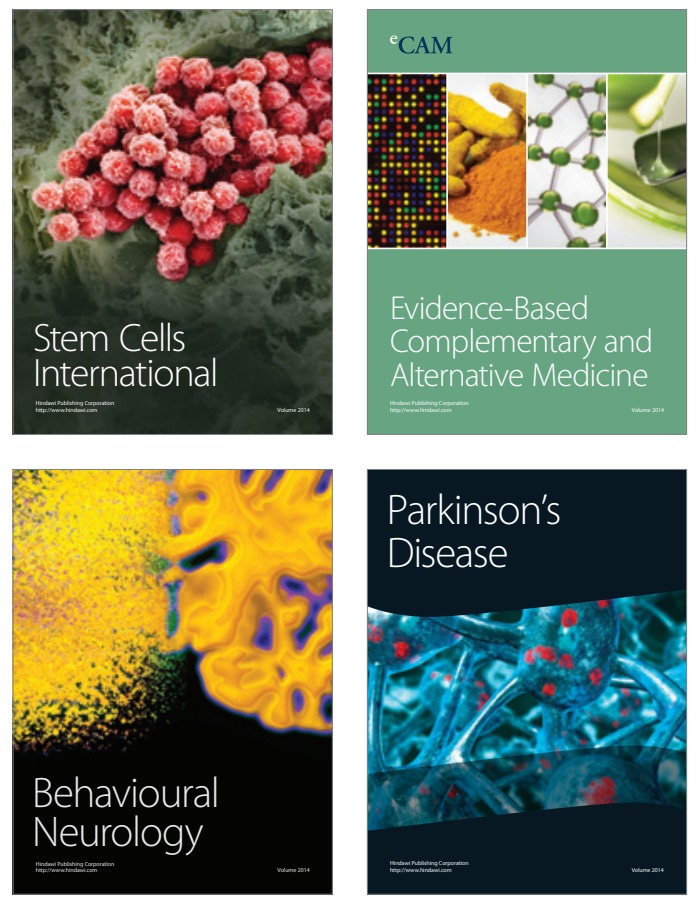
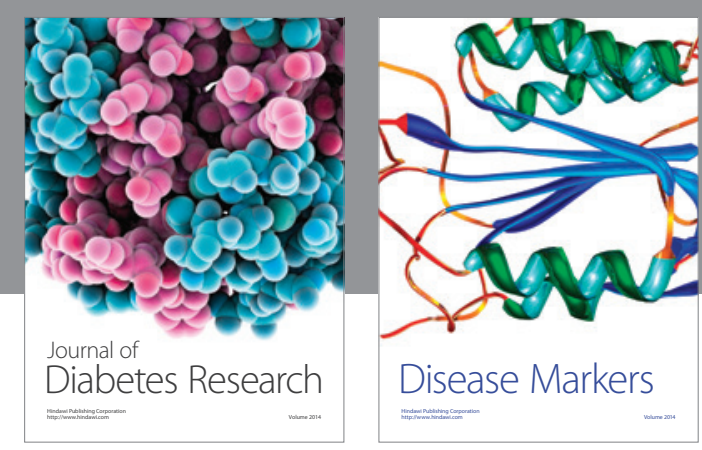

Disease Markers
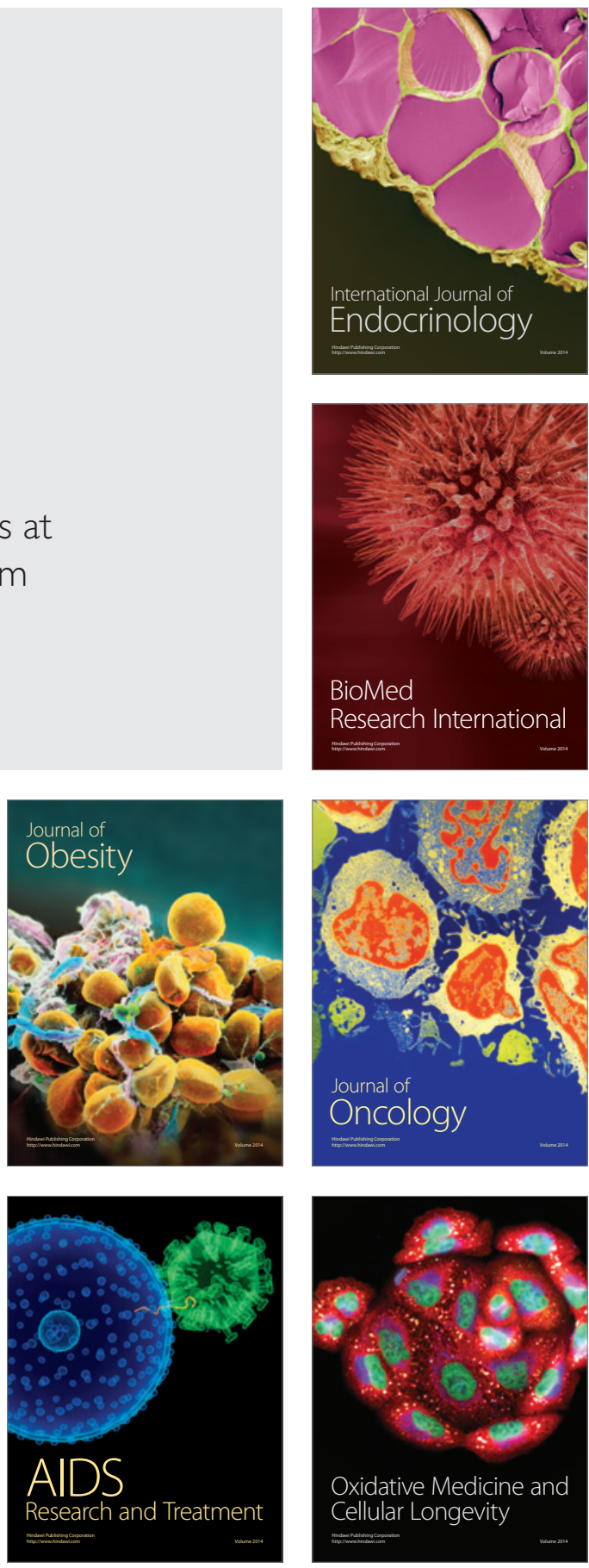